\title{
Correlation between clinical and ultrasonographic diagnosis in patients with first trimester vaginal bleeding
}

\author{
Gawade $S^{1}$, Virmani $S^{2}$ \\ ${ }^{1}$ Dr. Surekha Gawade, MBBS, DNB (OBGY), Assistant Professor, Department of Obstetrics and Gynaecology, Smt. \\ Kashibai Navale Medical College \& General Hospital, Pune, ${ }^{2}$ Dr. Smritee Virmani, MBBS, DGO, DNB, Assistant \\ Professor, Department of Obstetrics and Gynaecology, Smt. Kashibai Navale Medical College \& General Hospital, Pune, \\ Maharashtra, India
}

Address for correspondence: Dr. Surekha Gawade, Email: drsurekhagawade@gmail.com

\begin{abstract}
Introduction: Amongst the recent advances in obstetrical care, the introduction of ultrasonography has been a major contribution to improvement in prenatal diagnosis. The present study was conducted to correlate the clinical and ultrasonographic diagnosis in cases with bleeding per vaginum during the first 12 weeks of pregnancy. Material \& Methods: A total sample of 150 cases presenting with bleeding per vaginum in first trimester of pregnancy were included in the study. A detailed history and examination was done for all the cases to arrive at a provisional clinical diagnosis. All cases were then subjected to ultrasound examination for confirmation of diagnosis and a definite management was planned. Results: Maximum number of cases with first trimester bleeding per vaginum belonged to the age group of 18-27 years. Clinically, the most common diagnosis was threatened abortion $(86.67 \%)$ with remaining cases as missed abortion (5.33\%), incomplete abortion (4\%), ectopic pregnancy (2\%), hydatiform mole $(0.67 \%)$, threatened abortion with cervical polyp $(0.67 \%)$ and complete abortion $(0.67 \%)$. On ultrasonography also, the commonest diagnosis was threatened abortion (44\%) showing a discrepancy of $49.23 \%$, thereby, emphasising on a crucial role of ultrasonography in cases with first trimester bleeding per vaginum. Conclusions: Ultrasound is a very valuable aid in assessment of bleeding per vaginum in first trimester of pregnancy. After ultrasonography, treatment can be more accurately decided thereby saving time and cost of the patients as well as the healthcare system.
\end{abstract}

Keywords: Bleeding per Vaginum, First Trimester of Pregnancy, Prenatal Diagnosis, Ultrasonography

\section{Introduction}

The first trimester of pregnancy is a dynamic period that spans from fertilisation, implantation to organogenesis. It starts with the first day of last menstrual period and continues till the end of the twelfth week [1]. Bleeding in this trimester is a common presentation in the emergency room and is difficult to tackle, as a decision is to be made whether the pregnancy is viable or non viable and intrauterine or extra uterine [2].The main differential considerations of first trimester bleeding are spontaneous abortion, ectopic pregnancy or gestational trophoblastic disease [3]. About $25 \%$ of all gestations present with vaginal spotting or frank bleeding in the first few weeks of

Manuscript received: $20^{\text {th }}$ Oct 2015

Reviewed: $30^{\text {th }}$ Oct 2015

Author Corrected: $14^{\text {th }}$ Nov 2015

Accepted for Publication: $22^{\text {nd }}$ Nov 2015 pregnancy and half of these progress to miscarriage or abortion [4]. Clinical examination and hormonal studies are not always conclusive in making a definite diagnosis in these cases.

The application of ultrasonography in this context has an indispensable value because it is safe, quick, reliable and relatively inexpensive modality of investigation. It is a valuable non invasive tool to clinch the diagnosis [5]. The technique of ultrasound has revolutionised medicine in which echoes from deep within the body provide clues about its working and state of health. The first application of diagnostic ultrasound to obstetrics and gynaecology by Donald and associates has made a major contribution to improvement in prenatal diagnosis. 
The location, appearance and size of the gestational sac and presence of intact foetal echoes give the obstetrician a complete picture and help in initial management of the patient and also predict the outcome. The patient is relieved psychologically once the diagnosis is established [3]. Further, ultrasound is considered an asset with which the diagnosis is immediate and therapy can be planned depending upon the report. Keeping these factors in mind the present study was done to evaluate the role of ultrasound in diagnosis of bleeding per vaginum during first 12 weeks of pregnancy.

\section{Material and Methods}

This prospective study was carried out in the Department of Obstetrics and Gynaecology Sanjeevani Medical Foundation Research Centre, Pune with the aims to evaluate the use of ultrasonography in first trimester bleeding per vaginum. The study also aimed to correlate the clinical diagnosis with ultrasound diagnosis so as to know the correct line of management in doubtful cases.

One hundred and fifty cases with complain of bleeding per vaginum in the first trimester of pregnancy presenting to obstetrics and gynaecology OPD and emergency room were enrolled in the study. A detailed history and a comprehensive clinical examination including general, systemic, per abdomen and per vaginal examination were performed to arrive at a clinical diagnosis. The patients were then subjected to ultrasound examination following which a definite management was planned. Trans abdominal scan (TAS) was done with sector probe $3.75 \mathrm{MHz}$ frequency transducer. Transvaginal scan (TVS) using $6 \mathrm{MHz}$ probe was done where findings of TAS were inconclusive. TVS was also done in early gestation and in all cases of suspected ectopic pregnancy. Prior to TAS, a full bladder was ensured.

Management plan was decided on the basis of ultrasound diagnosis as follows. For cases confirmed with diagnosis of threatened abortion, management was conservative including hormonal treatment and regular follow up. Uterine evacuation was planned and conducted in confirmed cases of missed, incomplete abortion and vesicular mole. Cases of complete abortion were kept under observation and then discharged. Conservative/surgical management of patients with confirmed ultrasound diagnosis of ectopic pregnancy was done as per ultrasound findings and clinical condition of the patient.

Follow up scans were done in cases of threatened abortion till delivery and maternal and foetal outcomes were evaluated. Role of ultrasound in diagnosis and subsequent management of these patients who presented with first trimester vaginal bleeding was studied.

\section{Results}

Maximum number of patients who presented with first trimester vaginal bleeding belonged to age group $18-27$ years (70.67\%). As shown in Table-1, threatened abortion was the most common clinical diagnosis (86.67\%). Others were diagnosed as missed abortion (5.33\%), incomplete abortion (4.0\%), ectopic pregnancy (2.0\%), hydatiform mole $(0.67 \%)$, threatened abortion with cervical polyp $(0.67 \%)$ and complete abortion $(0.67 \%)$.

Table-1: Distribution of cases as per clinical diagnosis

\begin{tabular}{|l|l|l|}
\hline Clinical Diagnosis & Number of Cases & Percentage (\%) \\
\hline Threatened abortion & 130 & 86.67 \\
\hline Missed abortion & 8 & 5.33 \\
\hline Incomplete abortion & 6 & 4.0 \\
\hline Ectopic pregnancy & 3 & 2.0 \\
\hline Vesicular mole & 1 & 0.67 \\
\hline Complete abortion & 1 & 0.67 \\
\hline Threatened abortion with cervical polyp & 1 & 0.67 \\
\hline Total & $\mathbf{1 5 0}$ & $\mathbf{1 0 0}$ \\
\hline
\end{tabular}

On ultrasonography (Table-2) also, threatened abortion was the most common diagnosis (44\%) followed by missed abortion (22\%). Blighted ovum was a new diagnosis in $12.67 \%$ of cases which cannot be diagnosed by clinical methods. 
Table-2: Distribution of cases as per USG diagnosis

\begin{tabular}{|l|l|l|}
\hline USG Diagnosis & Number of cases & Percentage \% \\
\hline Threatened abortion & 66 & 44 \\
\hline Missed abortion & 33 & 22 \\
\hline Incomplete abortion & 9 & 6.0 \\
\hline Ectopic pregnancy & 10 & 6.67 \\
\hline Vesicular mole & 4 & 2.67 \\
\hline Complete abortion & 8 & 5.33 \\
\hline Threatened abortion with cervical polyp & 1 & 0.67 \\
\hline Total & $\mathbf{1 5 0}$ & $\mathbf{1 0 0}$ \\
\hline
\end{tabular}

Table-3: Comparison of clinical diagnosis with ultrasound diagnosis

\begin{tabular}{|c|c|c|c|}
\hline Clinical diagnosis & Number of cases & Usg diagnosis & Number of cases \\
\hline \multirow{7}{*}{ Threatened abortion } & \multirow[t]{7}{*}{$130(86.67 \%)$} & Threatened abortion & $66(50.77 \%)$ \\
\hline & & Missed abortion & $28(21.54 \%)$ \\
\hline & & Blighted ovum & $16(12.31 \%)$ \\
\hline & & Incomplete abortion & $8(6.15 \%)$ \\
\hline & & Ectopic pregnancy & $6(4.62 \%)$ \\
\hline & & Vesicular mole & $3(2.31 \%)$ \\
\hline & & Complete abortion & $3(2.31 \%)$ \\
\hline \multirow[t]{2}{*}{ Missed abortion } & \multirow[t]{2}{*}{$8(5.33 \%)$} & Missed abortion & $5(62.5 \%)$ \\
\hline & & Blighted ovum & $3(37.5 \%)$ \\
\hline \multirow[t]{2}{*}{ Incomplete abortion } & \multirow[t]{2}{*}{$6(4 \%)$} & Incomplete abortion & $1(16.67 \%)$ \\
\hline & & Complete abortion & $5(83.33 \%)$ \\
\hline Complete abortion & $1(0.67 \%)$ & Ectopic pregnancy & 1 \\
\hline Ectopic pregnancy & $3(2 \%)$ & Ectopic pregnancy & 3 \\
\hline Vesicular mole & $1(0.67 \%)$ & Vesicular mole & 1 \\
\hline $\begin{array}{l}\text { Threatened abortion with } \\
\text { cervical polyp }\end{array}$ & $1(0.67 \%)$ & $\begin{array}{l}\text { Threatened abortion with } \\
\text { cervical polyp }\end{array}$ & 1 \\
\hline
\end{tabular}

As shown in Table-3, threatened abortion was clinically diagnosed in 130 (86.67\%) cases. Amongst these, only 66 $(50.77 \%)$ cases were confirmed as threatened abortion by ultrasound. Remaining 64 (49.23\%) cases clinically diagnosed as threatened abortion were diagnosed as missed abortion $28(21.54 \%)$, blighted ovum 16(12.31\%), incomplete abortion $8(6.15 \%)$, ectopic pregnancy $6(4.62 \%)$, hydatiform mole $3(2.31 \%)$ and complete abortion $3(2.31 \%)$ on ultrasonography thereby emphasizing a crucial role of ultrasound in confirming clinical diagnosis of patients with first trimester vaginal bleeding. Amongst the $8(5.33 \%)$ cases clinically diagnosed as missed abortion, $5(62.5 \%)$ cases were actually missed abortion and the remaining 3(37.5\%) were blighted ovum on ultrasound. Also, amongst the clinically diagnosed 6 cases (4\%) of incomplete abortion, only 1 case $(16.67 \%)$ turned out to be incomplete on ultrasound and rest 5 cases $(83.33 \%)$ were complete abortions thereby indicating the superiorority of ultrasound in confirming clinical diagnosis. Further, one case diagnosed as complete abortion was found to be ectopic pregnancy on ultrasound. Cases clinically diagnosed as ectopic $(2 \%)$, hydatiform mole $(0.67 \%)$ and threatened abortion with cervical polyp $(0.67 \%)$ correlated well with ultrasound diagnosis. Ultrasound diagnosed cases with threatened abortion were followed up (Table-4). Out of the 66 cases, $45(68.18 \%)$ cases had full term vaginal delivery, 12 (18.18\%) cases had preterm vaginal delivery, 7 (10.6\%) cases aborted and $2(3.03 \%)$ cases underwent caesarean section. 
Table-4: Outcome of cases with threatened abortion diagnosed on USG

\begin{tabular}{|l|l|l|}
\hline Outcome of threatened abortion cases & Number of cases & Percentage \\
\hline Full term normal delivery & 45 & 68.18 \\
\hline Preterm vaginal delivery & 12 & 18.18 \\
\hline Abortion & 7 & 10.60 \\
\hline Full term caesarean section & 2 & 3.0 \\
\hline Total & $\mathbf{6 6}$ & $\mathbf{1 0 0}$ \\
\hline
\end{tabular}

\section{Discussion}

Diagnosis of cases with first trimester bleeding per vaginum was traditionally based on history, physical examination and clinical findings. Many times symptoms are misleading resulting in delay in diagnosis and treatment. Real time ultrasonography has now opened a complete new dimension in obstetrics in diagnosis of early normal and abnormal pregnancy. This has enabled us to institute immediate specific treatment (medical or surgical), thereby preventing mismanagement and saving time and cost.

In the present study, all cases with first trimester vaginal bleeding were selected for confirmation of clinical diagnosis by ultrasound. Majority of study population was in the age group of 18-27 years $(70.67 \%)$ which is the peak age group of fertility for women. In our study, threatened abortion was the most common clinical diagnosis $(86.67 \%)$ in patients presenting with first trimester bleeding per vaginum. Other cases were diagnosed as missed abortion $(5.33 \%)$, incomplete abortion (4.0\%), ectopic pregnancy $(2.0 \%)$, hydatiform mole $(0.67 \%)$, threatened abortion with cervical polyp $(0.67 \%)$ and complete abortion $(0.67 \%)$. Similarly, in a study carried out by Damania et al., 652 patients with first trimester bleeding were evaluated [6]. The most common clinical diagnosis amongst these patients was threatened abortion $(38 \%)$. Other cases were missed abortion (17\%), incomplete abortion (32\%), ectopic pregnancy (2\%), hydatiform mole (1\%) and complete abortion $(10 \%)$. Also, in a study carried out by Chaudhary et al. evaluating the role of ultrasound in first trimester vaginal bleeding, threatened abortion (55\%) was the commonest clinical diagnosis amongst the cases [7].

In this study, amongst the $130(86.67 \%)$ cases clinically diagnosed as threatened abortion only 66 cases $(50.77 \%)$ had similar diagnosis on ultrasound with a discrepancy of $49.23 \%$. Similar findings were observed by Iyer LJ et al. with a discrepancy of $51.35 \%$ [8]. In our study, it was observed that $22 \%$ cases were diagnosed as missed abortion on ultrasound. This was consistent with the findings of the study conducted by Reddi et al. in which $20 \%$ cases were diagnosed as missed abortion while evaluating patients with vaginal bleeding in the first trimester [9]. However, in a study conducted by Gorade et al. only $8.8 \%$ cases were diagnosed as missed abortion on ultrasound [10]. Higher incidence of missed abortion in our study may be contributed by cases attending late to the hospital due to lack of awareness amongst the patients and their carers.

A new diagnosis on ultrasound was blighted ovum. It is defined as an embryonic gestation characterised by a normal appearing gestational sac but the absence of an embryo. On ultrasound, $19(12.67 \%)$ cases were diagnosed as blighted ovum out of which 16 cases were diagnosed earlier as threatened abortion and 3 cases as missed abortion on the basis of clinical diagnosis. In a study by Sofat R. a similar incidence $12.2 \%$ of blighted ovum was observed on ultrasound [11]. In the present study, on ultrasound 8 cases $(5.33 \%)$ were diagnosed as complete abortion. However, clinically these cases were diagnosed as threatened abortion (3 cases) and incomplete abortion (5 cases). Hence, ultrasound helps in saving time and cost involved in medical and surgical management which would have been spent on these cases if diagnosis was solely on the basis of clinical evaluation.

In our study, we found $6.67 \%$ cases as ectopic pregnancy and $2.67 \%$ cases as hydatiform mole on ultrasonography. Other authors like Reddi et al and Sofat R. observed $21 \%$ and $8.8 \%$ cases as ectopic pregnancy and $18 \%$ and $5.55 \%$ cases as hydatiform mole on ultrasound respectively [9,11]. Higher incidence reported by them was due to higher age group of patients in their study as rate of ectopic and molar pregnancy increases with age. Also, prevalence of molar pregnancy varies with race and population. We also followed the outcome of cases with threatened abortion (as per ultrasound diagnosis) in our study. Out of the 66 cases of threatened abortion, 45 cases $(68.18 \%)$ had a full term vaginal delivery, 12 cases $(18.18 \%)$ had preterm vaginal delivery, 7 cases $(10.6 \%)$ 
aborted later and 2 cases $(3 \%)$ had full term caesarean section. In our study, amongst the cases that were diagnosed as threatened abortion on ultrasound, $89.36 \%$ had a successful pregnancy outcome. A similar successful pregnancy outcome $(87 \%)$ was observed in a study carried out by Mantoni et al. [12]. Also an incidence of prematurity following threatened abortion was $19 \%$ as reported by Verma et al. [13] which was comparable with our study. Hence it can be concluded that ultrasonography is a very valuable aid in the assessment of early pregnancy development. It is the only visual means of doing so. It represents an objective, non-invasive and biophysical means of defining the early gestation and its abnormalities with accuracy superior to any other known methodology. After Sonography, treatment can be more accurately decided and better patient care can be provided than merely relying on clinical diagnosis alone, hence making it a great boon to the obstetricians in the modern era.

\section{Funding: Nil}

Conflict of interest: None.

Permission of IRB: Yes

\section{References}

1. Graham GM. Ultrasound Evaluation of Pregnancy in the First Trimester. Donald School Journal of Ultrasound in Obstetrics and Gynecology, JanuaryMarch 2010;4(1):17-28

2. Dogre V, Paspulati RM, Bhatt S. First trimester bleeding evaluation. Ultrasound Q.2005;21:69-85.

3. Dighe M, Cuevas C, Moshiri M, Dubinsky T, Dogra VS. Sonography in first trimester bleeding. J Clin Ultrasound. 2008 Jul-Aug;36(6):352-66.
4. Paspulati RM, Bhatt S, Nour SG. Sonographic evaluation of first-trimester bleeding. Radiol Clin North Am. 2004 Mar;42(2):297-314.

5. Padmaja P, Somashekhar S. First trimester vaginal bleeding-Evaluation by Ultrasound. Indian Journal of Applied Research. 2015 Jun;5(6):391-394.

6. Damania KR, Purandare CB. Role of ultrasound in management of first trimester haemorrhage. J Obst and Gynaec India.1987;37:195.

7. Chaudhary V,Sharma S,Chaudhary G. Ultra Sonographic Evaluation of First Trimester Vaginal Bleeding. Journal of Advanced Researches in Biological Sciences. 2011; 3(2): 60-62

8. Iyer LJ, Bhattacharya M. Role of Ultrasonography in early pregnancy complications. J Postgrad Med. 1992;38:115

9. Reddi RP, Sunita V. Ultrasound evaluation of vaginal bleeding in first trimester pregnancy. J Obst and Gynaec India. 2000;50:54-58.

10. Gorade TG, Shorothri AN. Ultrasonography in early pregnancy bleeding. J Obst and Gynaec India.1991;41:13-16.

11. Sofat R. Ultrasound evaluation of bleeding in early pregnancy. J Obst and Gynaec India.1987;37:344-347.

12. Mantoni M. Ultrasound signs in threatened abortion and their prognostic significance. Obstet Gynecol.1985;65(4):471-5.

13. Verma SK, Premi HK, Gupta TV, Thakur S, Gupta KB, Randhawa I. Perinatal outcome of pregnancies complicated by threatened abortion. J Indian Med Assoc. 1994 Nov;92(11):364-5.

\section{How to cite this article?}

Gawade S, Virmani S. Correlation between clinical and ultrasonographic diagnosis in patients with first trimester vaginal bleeding. Int J Med Res Rev 2015;3(10):1188-1192. doi: 10.17511/ijmrr.2015.110.214. 